\title{
Research on Applications of Regional Culture Elements in Logo Design
}

\author{
Fei Fang
}

Shandong Agriculture and Engineering University, Jinan, 250100, China

Keywords: Regional culture, Logo design, Tourism image

\begin{abstract}
Different regions have different regional cultures. The applications of regional culture in logo design can enrich the connotation of logo and its uniqueness also avoids the identical defects of logo design in today's market. At present, the main fields of the applications of regional culture elements in logo design are the tourism logo design, university logo design and postcard logo design. This paper gives the application paths of the regional culture elements in logo design in the above three fields to provide some references for the relative researchers.
\end{abstract}

\section{Introduction}

The connotation of regional culture refers to the behavior mode and mode of thinking of a specific group within a certain space [1]. The different behavior and thinking patterns of people in different regions lead to the different geographical and environmental factors of regional culture, social and humanistic factors and their interaction, which are the main factors for the formation of regional culture. At the same time, regional culture has stability and inheritance, it is in a relatively stable environment, in the natural geographical environment and human and social factors and other factors under the role of a considerable historical period of gestation and formation. Regional cultural differences will form different regional cultural characteristics, which will inevitably have a profound impact on the selection, conception and refinement of tourism image signs, thus forming a symbol with strong regional cultural characteristics. Tourist image signs full of regional characteristics concentrate a local folk custom, bearing its specific aesthetic functions and significance, with other tourism image signs cannot be compared with the irreplaceable. The history of logo design can be traced back to very old times. Because of the innovation and development of economy and politics, logo design has gradually developed into an important art design category from a simple and primitive form. It plays an extremely important role in today's social life. Logo can be said to be like a recognition mark, but the logo is not as simple as the mark, is a meaningful graphics, and has rich symbolic meaning. Logo is also like a code name, but this code is visual, giving and expressing more connotative meaning. A good sign can convey its meaning without words. In modern society, we can see many logo designs which are related to regional cultural elements [2].

\section{Range of Applications of Regional Culture Elements in Logo Design}

\subsection{Tourism Logo Design}

Regional culture is the creative source of tourism logo design. It can not only reflect the cultural attributes of the tourist destination itself, but also break the homogeneity of the tourist destination, so that consumers can be clearer about the characteristics of the tourist destination they want to choose [3]. Tourism image logo design is based on the local regional cultural characteristics, and presents to tourists is a unique cultural, distinctive personality of the tourism logo. Moreover, the process of acceptance, understanding and perception of tourism image signs is inseparable from their understanding of the regional culture of the tourist destination. In the design of tourism logo, the logo design under different cultural backgrounds should have strong identification and difference both in image and connotation, and clearly convey the personality of tourism destination in the logo. Tourism logo design is an innovative thinking activity. In the process of thinking, we need to analyze and 
summarize the regional culture to find the best graphic creative expression of tourist destination, and strive to create a unique regional cultural logo. Creativity embodies the designer's individual wisdom and plays a key role in the overall process of tourism logo design, including the innovation of thinking, elements and forms of expression. Logo design is always seeking new and changing, striving to maintain long-term vitality. Only by constantly exploring and transcending, finding a new breakthrough point from people's inertial thinking, enhancing visual perception and appeal, and producing a surprising effect, can the information conveyed by the sign penetrate the hearts of the people and enhance the persuasiveness of the tourism image sign. Designers must deeply analyze the local tourism culture, study the image design of similar tourist sites on the market, collect a large number of typical tourist signs of similar tourist sites at home and abroad, and summarize the reasons for their design success or failure.

\subsection{University Logo Design}

University logo is a graphic design that expresses the university's spiritual concept, history and culture with easily recognizable graphics, characters and other symbols. Logo is one of the elements in the visual image recognition system of a university, and it is also a concentrated expression of the overall image of a university. The success of university logo design can not only make it easy for the public to accept and remember, but also help to establish a good university brand image in a reasonable use. Various elements in regional culture are not only a figure or pattern, nor a symbol of a certain meaning, but a concentrated reflection of our traditional art and culture. Regional cultural elements can be used in many aspects of the design, but also naturally in the university logo design will be presented. University logo design materials, design techniques, creative points can also be completely extracted from the regional cultural elements. Regional cultural elements have the common attributes of general symbols: as a carrier and transmission of information media, through artistic processing and integration to achieve the purpose of conveying feelings. At the same time, regional cultural elements can also play a role of conversion, that is, cultural value into economic value and social value, which coincides with the design requirements of modern university logo. A university logo, only strictly in accordance with the logo standardization to apply, in order to better maintain the authenticity and authority of the university logo. At the same time, in the era of globalization, Chinese university logo design is gradually in line with international standards, university logo design to keep up with the pace of the world, with a broad vision. Only the national is the world. The ingenious use of regional cultural elements in university logo design can well meet the trend of internationalization of university logo design. We should use new design concepts and regional culture elements to enhance the individualization of university signs [4].

\subsection{Postcard Logo Design}

Creative postcards refer to the extension of the form of postcards, to expand new ideas, the use of postcards as a widely accepted and used way of communication for the carrier, in the design of the original, personalized, regional characteristics and the flavor of the times diversified postcards. Through the new visual experience, to achieve the purpose of cultural communication and communication, to improve China's tourism market, promote regional cultural characteristics and the development of cultural and creative industries have a positive role in promoting. As the interface of vision and communication, creative postcards are free to choose according to the different needs of the audience, to a great extent, to meet the individual psychological desires. As a creative idea, highlight different regional cultures, to collect stamps, collection, commemoration and appreciation of the way to retain, emphasizing the cultural heritage of regional vision. As a commodity, creative postcards break through the ordinary, enhance the mind, seek personality, and provide a variety of choices for the audience. In a sense, creative postcards are a new variety based on the platform of cultural and creative industries. Creativity and practicality coexist, choice and hobby coexist, regional culture and world culture coexist. Regional visual features refer to the local famous, unique visual characteristics of the image and landscape, and is recognized by the public as a visual symbol. Regional vision is built on the basis of regional culture, through the excavation, inheritance and 
development of cognitive brand. It has its own distinctive personality, prominent image, the characteristics of differentiation, in people's minds occupy an important position. Regional vision shows the local customs, cultural heritage and natural phenomena in the form of landscape, image and symbols. Regional vision and communication are inseparable, with cultural exchanges increasing and upgrading. Therefore, regional vision: one is a way of reproduction, intuitive expression of regional image, one is a creative way to break through the concept of regional culture, to create a new visual image.

\section{Models of Applications of Regional Culture Elements in Logo Design}

\subsection{Image Model}

For logo graphics, its main purpose is to identify simple content and unique forms of expression of local history, culture and architecture. Therefore, in the design of tourist signs, local cultural characteristics and cultural connotations should be included, but because a place has more tourism resources. The content of the design is more complex, and the content of the logo graphics can be relatively less. In the process of design, we need to choose the most representative and well-known things to reflect the local culture and characteristics, and then through the abstract graphics and artistic processing means to design graphics. This design method can not only increase the visual impact of tourists, but also increase the interest of tourists in the tourist destination, attracting the attention of tourists. In School Logo design, logo graphics is the most important factor, but also a direct impact on people's visual sense of the elements. Accurate graphic expression can make school logo and audience interact and resonate. The contents of school signs need to be expressed by specific element symbols. These elements contain rich ideological content. To convey a clear message, it must be based on the audience's understanding and recognition of these meanings. Postcard graphics, as the main language and expression means of vision, highlights the conceptual and visual effects in the design. In creativity, the graphic itself acts as an exchange carrier, participates in the communication way, and conveys the theme intention. The regionality of graphics is to find more specific situations and typical symbols, to memorize images, to express ideas and behavioral intentions. To a large extent, recognize new graphics and symbols, enhance visual level and cause concern.

\subsection{Color Model}

For tourism signs, the color is not only a kind of color that can represent the local cultural characteristics. At the same time, it can also reflect the local customs and feelings, through the embodiment of different color elements, forming a centralized expression of local culture. When choosing the colors of tourist signs, not only the designers need to make a detailed survey of the local customs and customs, but also need to refine and integrate the local landscape and landscape and many other elements. In addition, color selection also needs to combine the emotional preferences and emotional needs of the main local consumers. Regional culture is an important source of inspiration for the design of tourism signs. It can not only make the tourism signs have local cultural characteristics, but also break through the current uniform form of tourism signs, so as to better reflect the local characteristics and attract the attention of tourists. Therefore, in the design of tourist signs, it is necessary to combine the local unique cultural characteristics, display the local culture different from other regions to tourists. In addition, the design of tourist signs needs to be simple and easy to accept, so that tourists can understand the unique landscape characteristics of the local more clearly. Digital is the use of modern technology, to expand visual creativity, from the way to change the original graphic design of the status quo. Digital expression extends people's concepts and thinking modes infinitely in the given visual space, greatly enriching the visual mode and effect brought by creative behavior. Influenced by computer technology, creative postcards use two-dimensional, three-dimensional software to process pictures, text and other elements, through the special effects provided by the software to try different changes. This is the expression of design 
technology in the information age. It is a man-machine integration and experience on the interface. Therefore, the use of digital regional performance is conducive to the combination of technology and creative forms of specific visual effects. In logo design, the application of color is very important, color is the first key to grasp people's vision, especially in long-distance recognition. Graphics and text visual impact is a very important visual element, color with its bright, eye-catching visual communication and symbolism in logo design plays a huge role. Color purity is also very high with a strong regional and national characteristic.

\subsection{Text Model}

As an important invention of mankind, written symbols can communicate information through specific symbols. Therefore, it is indispensable for the design of tourism symbols. Proper written symbols can play a key role in the design of tourism symbols. Show to tourists, and Chinese characters have a very unique and beautiful image, can be expressed through the text of the content simply presented to tourists, so that tourists simply understand the local characteristics. When choosing the symbols of tourist destination signs, it is necessary to use some simple and easy-to-understand words to present the local characteristics to the tourists quickly and accurately, so that they can quickly understand the local tourism characteristics and facilitate the tourists to choose. The key point of symbolic font delivery design is that it aims at transmitting information quickly and accurately. It uses easily recognizable symbols and functions to convey potential artistic information. It highlights the function of tourism signs and the internationalization of symbol design. Characters play an irreplaceable role in other design elements, and have deeper connotation and special artistic attraction. Many successful tourist signs use the name or text of the tourist destination as the theme of the design, at a glance. Excellent design can often endow the text with regional cultural connotation, combined with regional characteristics for reprocessing, design a full expression of the font image. Literal forms include the first, initials and abbreviations. Character itself is a very aesthetic figure, with the characteristics of understanding, hieroglyphic, referring to things, transferring notes, borrowing and other forms. The creative method starting from words is a symbol design form used by university at present. Today's society is a brand-building society, especially for tourism. In the design of tourism logo, we need to constantly improve the degree of optimization of tourism resources, and integrate it into it, so that its style can exist for a long time. In the process of building regional cultural brand of tourism signs, we need to maintain their own characteristics and personality to ensure their own characteristics different from other tourist destinations.

\section{Conclusion}

With the re-excavation of the long-standing regional culture, modern people have gradually realized the important role of regional culture in modern social communication, especially in logo design. As a symbolic symbol of mass communication, logo is an important part of culture and image building. Its design, sampling and design techniques can be extracted and innovated from the elements of regional culture. We can use regional cultural elements to design better tourism logos, university logos and creative postcards.

\section{References}

[1] Zheng Zhiming, Jiang Rong, Meng Ying. City Design for Urban Gateway Area Based on Regional Culture: A Case Study of the Guangyuan Railway Station Area [J]. Journal of Landscape Research, 2018, 10(2): 106-108.

[2] Peng Jun. Impact of Regional Culture on Tourism Image Logo Design [J]. Packaging Engineering, 2012, 33(4): 15-18.

[3] Li Tong, Li Zhongyang. The New Regional Path— Research on the creative postcard design according to the characteristics of vision of regional culture [J]. Design, 2015(1): 136-145. 
[4] Ye Jundong. Application of Regional Culture Elements in Modern Logo Design [J]. Packaging Engineering, 2017, 38(8): 198-201. 